\section{ANXIETY PSYCHONEUROSIS.}

\section{BY ALFRED CARVER, M.D., D.P.M.CAMB. \\ (From the Birmingham Clinic for Functional Nervous Disorders.)}

THE English language contains no single word which exactly expresses the meaning of the German "Angst" or the French "angoisse." "The word "anguish" is generally too strong, while "anxiety," as commonly used, is far too weak-e.g., anxiety to catch the post or a certain train is expressed in everyday speech. The latter term requires qualification when applied to that type of anxiety experienced and manifested by the psychoneurotic. Were mental factors alone under consideration the term "morbid anxiety" 1 would be appropriate, but as the physical concomitants of this mental state must also be taken into account some term which includes them is desirable. This has been sought by such designations of the total symptomcomplex as anxiety neurosis, anxiety hysteria, anxiety state, or, more rarely, anxiety psychoneurosis. The first two of these terms unfortunately stress a subsidiary hypothesis rather than the essential morbid anxiety. The term anxiety neurosis was introduced by Freud to describe a group of cases in which the symptomatology was considered to depend upon an actual physical tension. Since its introduction the term has been loosely and ignorantly used. Freud, of course, did not imagine that all morbid anxiety was thus determined; indeed, in a paper on "wild psychoanalysis," he states explicitly that "he who suffers from morbid anxiety is not necessarily the subject of an anxiety neurosis." Further study has shown that in all casies of morbid anxiety, even where a physical origin might be assumed, the mental factor always coexists and is the more important of the two. The term anxiety hysteria signifies that the mental mechanism concerned in the production of the symptoms is similar to that operative in other forms of hysteria. Unfortunately there is no general agreement as to what constitutes hysteria, and many different definitions are current at the present day.

Morbid Anxiety.

The term psychoneurosis does not labour under such great disadvantages, and if it be confined, as it should be, to functional nervous disorders with predominantly mental symptoms due to emotional disturbances the designation anxiety psychoneurosis would be most appropriate to that group of cases the main symptom of which is morbid anxiety with its physical con. comitants. Defined in this way, anxiety psychoneurosis is the commonest of the many neurotic disturbances which have arisen out of the war, yet it has not received the amount of attention which its importance warrants. This is probably due to the fact that the more showy somatic dissociations, which, following Freud's nomenclature, are now termed conversion hysterias, absorb the attention of a majority of workers in this field of medicine. Upon closer study, however, morbid anxiety is found to be the primary mental disorder upon which the other psychoneuroses are built as superstructures, most of the superimposed symptoms

1 The morbidity of the anxiety consists in its being out of proportion to the apparently exciting cause.

(Continued from previous page.)

Boldt (H.J.).-9. High Degree of Heat versus Low Degree of Heat as Palliative Treatment for Advanced Cases of Carcinoma of the Uterus, with Autopsy Report of a Case treated by Long Application of Low Heat, as advocated by Dr. J. F. Percy, Amer. Jour. Obstet., 1916, Ixxiii., 1-15. 10. High Degree of Heat versus Low Degree of Heat in the Treatment of Cancer of the Uterus, Trans. Amer. Gynec. Sec., 1916, xli., 552-556. 11. Ibid., 542-551.

Percy (J. F.).-12. Heat as a Method of Treatment in Some Forms of Cavity Carcinoma, Amer. Jour. Obstet., 1917, 1xxv., 87-97.

Corscaden (J. A.).-13. Specimen from an Autopsy 18 Nonths after Percy Cauterisation for Carcinoma of the Uterus, Amer. Jour. Obstet., 1918, 1xxvii., 826-832, Med. Rec., 1918, xciii., 745. 14. Report of Two Fatal Cases following Percy's Low Heat Treatment, John's Hopkins Hos. Report, 1919, 305. 15. Leitch, Archives Middlesex Hospital, 1906. being produced as the result of an effort to defend the Ego from the baneful effects of morbid anxiety.

At the present time few cases of conversion hysteria are met with among pensioners, while a high proportion of those coming before the neurological boards and clinics is found to be suffering from morbid anxiety alone. The reason for this need not now detain us, but if the view that in the psychoneuroses morbid anxiety is the primary mental disturbance be granted, one would expect to meet it uncomplicated in many early and slight cases, and as a corollary of this the removal of any superimposed protective symptoms which had temporarily masked morbid anxiety would, unless further and more radical treatment were employed, allow it again to become manifest. Experience shows that this is unfortunately of frequent occurrence, especially with conversion hysterias.

\section{Symptoms of Morbid Anxiety.}

Before entering into the psychopathology of morbid anxiety, it will be well briefly to survey the symptoms as exhibited by a moderately severe case. There is the typical anxious facies, the startled and strained expression with widening of the palpebral fissure and dilatation of the pupils; the speech, even if not definitely stammering, is characteristic; tremor and hyperhidrosis are almost invariably present. Respiration is shallow but hurried; there is tachycardia, experienced subjectively as palpitation or jumping of the heart. Often a sinking or fluttering sensation in the epigastrium is complained of and may be associated with diarrhœea and frequency of micturition. All the above symptoms indicate an overactivity of the vegetative nervous system and are recognisable as the physical concomitants of the emotion of fear. Yet as a rule the patient does not lay stress upon any of these symptoms nor, unless definite phobiæ have developed, does he realise that he is in any way suffering from fear. He complains rather of being easily upset, of headache, irritability, inability to concentrate, and easy fatigability; of bad dreams, and lack of sleep. It is this group of symptoms and not those previously enumerated which render him unable efficiently to carry out his daily work. Being easily upset is, in the absence of a definite phobia, always the cardinal symptom.

\section{Use of Psycho-analysis.}

As physical examination leads us no fartber we must proceed by some method of mental exploration to inquire into the psychopathology underlying the production of the symptoms. Suppose we adopt analysis. The analyst asks the patient to relate freely everything he can about himself. The patient generally starts off well pleased, for there is nothing that the neurotic likes better than a sympathetic audience; but in this case he has reckoned without his host. Very soon the alert analyst notices hesitation, pauses and hiatuses in the story, or that his patient is getting uneasy, perhaps even showing an increase of tremor or sweating. The analyst, who has hitherto been passive though very much on the qui vive to detect such signs or any of the subterfuges by which they may be masked, now urges the patient and keeps him to the task, never allowing him to slur over or treat impersonally any subject which is coming up in his mind. The analyst must urge and encourage the patient, and must interpret to him the significance of any method of evasion which is either consciously or unconsciously employed, but in so doing must scrupulously avoid making any suggestions to him. By this means the patient is gradually brought to unfold his personality and the resistances are broken down. It has been found more advantageous to proceed by this method than to attempt a direct attack upon the symptoms while the resistances are still in force. The need for overcoming the resistances and bringing out the dissociated and repressed experiences in their minutest detail is exemplified by the following case :-

A soldier, in the R.F.C. at the outbreak of war, developed in 1917 an anxiety psychoneurosis after crashing near his aerodrome in France. He described the actual crash without much difficulty, but although he D 2 
had been conscious after the fall he showed an amnesia from that time until he found himself in the aerodrome again. This might easily have escaped notice, yet it contained an important clue to the cause of his morbid anxiety. Great pressure was needed before he could fill in that gap, but eventually the following story came to light. As he was being carried to the aerodrome he had to pass a spot where a great friend of his had previously crashed with fatal results. A rescue party, which included the patient, had set out on that occasion, but as they neared the spot the bombs on the crashed and now flaming aeroplane had detonated, killing several of the party.

The intolerable idea from the recollection of which he shrank was thus not his own crash. One might have been satisfied that in uncovering the second experience, which recalled the death of his friend, one had reached the root of his trouble. But the full story was not yet told; it appeared later that when the bombs on the burning aeroplane had detonated and killed some of the would-be rescuers, one of the party, mortally wounded, was hurled against the patient, knocking him down and falling on top of him. Lying upon the patient, this man died, a convulsive tremor shaking his body. It was the idea of this experience, seeking to return to his mind as he passed the spot, which was to the patient so intolerable that he "forgot" all about it. It is this "forgetting" of experiences with an unbearable affective tone which Freud has termed repression, and repression is the very foundation-stone of Freudian psychology and of psycho-analysis.

\section{Repression: Substitution.}

The development of symptoms is not an immediate result of repression, but is due to what Freud terms the return of the repressed material, which can take place only when certain conditions are fulfilled. The aim of repression is to keep from consciousness the unpleasant affective element of an experience. With this intent the whole experience is repressed. So long as it can be fully maintained the repression may be described as successful, but if only the ideational element of the complex is excluded from consciousness, while its affective element disturbs consciousness in the form of morbid anxiety or other symptoms there is a partial failure of repression. The anxiety properly appertaining to the dissociated idea now manifests itself in connexion with a suitably associated idea. That is to say, another idea is substituted for the repressed one, and the disagreeable effect is displaced on to the former. Displacement continues to spread for it does not matter what is feared so long as it is something other than the original excitant of the emotion. Thus in course of time almost any dis agreeable stimulus becomes capable-of stimulating the complex through substitution, and so of affording an outlet to its affective element. This accounts for what was emphasised as the cardinal symptom in morbid anxiety-viz., "being easily upset." If a suitable symbolic idea is substituted for the ideational element of the complex a phobia for the object of this idea is developed. Morbid anxiety may then arise either through the spontaneous activity of the complex, or through its stimulation, symbolically, by the object for which a phobia has developed.

For effective treatment of the condition the repressed idea which is symbolised by the object must be brought to consciousness. No amount of common-sense reassur ance is adequate to free the patient from his phobia which, indeed, he himself recognises as irrational. When, however, he can be brought to overcome the resistances determining the repression which motivated the development of his phobia the latter soon loses its morbid power over him. The soldier of whose history a fragment has already been given had a phobia for long narrow passages. Naturally he avoided such places, but if ever he did attempt to force himself to go into one a condition of panic ensued. We see, then, that the phobia is in a sense protective, its function being to keep the patient away from situations or objects which by stimulating his repressed complex produce in him a state of acute morbid anxiety or panic. Superficial analysis of the phobia of long narrow passages showed it to be connected, via the incidents already recorded, with repressed experiences which had occurred in some caves on the retreat from Mons, although, be it remembered, the patient had been a fit flying man during three years after these experiences. Great resistance was encountered in overcoming this repression, which finally was only cleared up by the aid of analysis of a recurrent dream. Into this there is no need to go ; it is sufficient to indi cate, in passing, the great help which in such cases may be derived from dream-analysis. A legitimate question which obtrudes itself here is as to whether a superficial analysis such as that fragmentarily reported above-which, nevertheless, sufficed to remove the patient's symptoms-is all that ought to be attempted. Can it be said that the patient is cured when his symptoms have been removed in this way? Is not the condition upon which they were enabled to develop left untouched? From the practical point of view we must generally rest satisfied when the symptoms have been relieved; yet during the course of an analysis even so superficial as that recorded above, glimpses are caught of deeper-lying repressed material, and we are compelled to inquire whether the repressions of later life can come about de novo in an individual whose previous development has proceeded harmoniously. Freud, by tracing the psychic ontogeny both of neurotic and of apparently normal ${ }^{2}$ individuals, has answered this question in a very emphatic manner though, needless to say, his answer has not met with anything like general accord. As a result of his studies Freud has come to the conclusion that "the repressions of later life are only possible in regard to the deriva. tives or other connexions of the primordial repressions which take place in infancy." Had Freud stopped here it is possible that few would have contradicted him, but after going on to show that morbid fear is only the obverse aspect of desire, he argued that in ultimate analysis all desire is "sexual" in origin. (It must be borne in mind that Freud's conception of sexuality is much wider than the current connotation of the word, so that even the admissibility of the term "infantile sexuality" has been hotly disputed.) The individual's primitive "sexual" wishes undergo repression in the course of his development, because they are repugnant to the standards of his later developing egoideal. According to Freud, it is upon this primordia basis alone that the repressions of later life are build. able and are built. In any case it is always a failure of adaptation to existing circumstances which leads to regression, and thus revives former modes of reaction. The later events, which are commonly regarded as causal, only play the rôle of favouring, through regression, a return of the repressed material.

\section{Conclusion.}

What the subject of morbid anxiety really fears is, therefore, in ultimate analysis his own primitive desires, or, more tersely, a part of himself. In conclu sion, I would add that, so far as my experience goes, it is rarely necessary in the true war anxiety psychoneuroses, where the factors determining regression are quite unusually severe, ${ }^{3}$ that mental exploration should proceed so far as the deepest levels; but in some of them, as in most civilian cases, it is therapeutically needful as well as scientifically interesting to reach the level of the primordial repressions.

2 The normal individual is only a scientific abstraction.

In war cases, as I have previously pointed out (THE LANCET 1919 , ii, p. 193) dissociation may occur as the result of a sudden physical shock without prior morbid anxiety. Subsequently, how he tries to repress the recall of this disagreeable experience symptoms of morbid anxiety develop.

School Clinic at Poole (Dorset).-A new school clinic has recently been opened at Poole, the mayor officiating at the ceremony at which many of the local teachers were present. The clinic consists of dental and refraction rooms, waiting- and bath-rooms, and a welllighted and well-equipped laboratory. The attendance of mothers seeking advice as to young infants is encouraged in the hope of linking up infant welfare and school work as a means towards establishing a public health conscience a mong the people. 